\title{
Strategic Decision Making: Process, Models, and Theories
}

\author{
Anwar Ahmed (Corresponding author) \\ Department of Business Studies, Technical University of Mombasa \\ P.O.BOX 90420-80100, Mombasa, Kenya \\ Tel: 254-711-572-412Ｅ-mail: ahmedah@tum.ac.ke
}

Henry Bwisa

School of Human Resource Development

Jomo Kenyatta University of Agriculture and Technology

P.O. Box 62000, 00200 Nairobi, Kenya

Tel: 254-722-858-507Ｅmail: bwihem@yahoo.com

\begin{abstract}
Romanus Otieno
Jomo Kenyatta University of Agriculture and Technology

P.O. Box 62000, 00200 Nairobi, Kenya
\end{abstract}

Tel: 254-714-491-445Ｅmail: romanusemod@yahoo.com

\begin{abstract}
Kabare Karanja
Jomo Kenyatta University of Agriculture and Technology

P.O. Box 62000, 00200 Nairobi, Kenya
\end{abstract}

Tel: 254-722-964-988Ｅmail: kabarekaranja@gmail.com

Received: March 11, 2014 Accepted: March 26, $2014 \quad$ Published: June 5, 2014

doi:10.5296/bms.v5i1.5267ＵRL: http://dx.doi.org/10.5296/bms.v5i1.5267 


\section{Abstract}

The theories and models underpinning strategic decision-making (SDM) are somewhat eclectic that demand multidisciplinary approach and appears non-differential from decision-making (DM) theories. This paper is a first attempt that puts the discipline into perspective of its coherent whole. We start by defining strategy and SDM in order to set the expectations for the rest of the paper. Next, we make an outline on the contribution of management science (MS) to SDM before establishing the relationship with MS and its application to micro, small, and medium enterprises (MSMEs). Subsequently, we make a discussion on the SDM process, SDM theories and models before concluding that the discipline has reached maturity.

Keywords: Strategic Decision Making, Decision Making, Management Science, MSMEs 


\section{Introduction}

The study stems from an extensive work done on the role of MS in supporting strategic decision making right from the academics to the practical application. Although MS's relationship with strategy is not very old, it appears to have been necessitated by the desire to undertake good analysis, and the wish to manage the complexity that surrounds strategy making if systematically feasible and culturally desirable outcomes are to be generated (Franco, 2011).

There are at least a dozen different views on strategy (Mintzberg \& Lampel, 1999; Tsoukas \& Knudsen, 2012) that is derived from Greek words “stratos” and “agein”. When combined into the term "strategos" it means the art of troop leader, office of general, command or generalship (Bailey, 2007). In military context, strategy refers to the art and science of identifying, assembling, and marshalling troops and equipment of war in a manner that must guarantee the complete defeat of the enemy.

Bailey (2007) enumerates different definitions of strategy in the context of business management summarized as a way of action that is necessary to achieve the main goal given scarcity of resources. In other words, it is about gaining a competitive advantage over adversaries given a set of options. Nichols (2010) makes a distinction on three forms of strategy: (1) general strategy, (2) corporate strategy, and (3) competitive strategy. The first form relates between ends and means or the results we seek and the resources at our disposal. On the other hand, corporate strategy relates to the environment in which the company operates while competitive strategy defines the basis in which the company competes.

Decisions are at the heart of success, and at times there are critical moments when they can be difficult, confusing, and nerve racking. A decision usually involves three steps: (1) A recognition of a need - a dissatisfaction within oneself (a void or need); (2) a decision to change - to fill the void or need; and (3) a conscious dedication to implement the decision (Arsham, 2010).

Making the right decisions is not only what someone wants to do, but also includes what he has to do. On one hand, the repercussions of not making a decision could be more severe than making a wrong decision. However, the fear of making the wrong decision is what drives us to utilize a scientific approach; and this is exactly what MS and SDM is all about. In fact, with its phased process, MS goal is to eliminate decidophobia (Arsham, 2010).

According to Papadakis and Barwise (1998a, p.1), “SDM is of great and growing importance because of five characteristics of strategic decisions: They are usually big, risky and hard to reverse having significant long-term effects, they are the bridge between deliberate and emerging strategy, they can be a major source of organizational learning, they play an important role in the development of individual managers and they cut across functions and academic disciplines”.

In spite of the many studies that reveal MS practitioners to be legitimate strategic actors 
within organizations as noted by O’Brien (2011), there are still several debates on the contribution of MS to SDM. MS often undertakes the following roles:

i. Modeling: MS has developed extensive models that aid SDM process; of particular interest are the MCDA that deal with decision problems under the presence of a number of decision criteria.

ii. Integration of models and mixing of methods: In emerging SDM trends, the resultant model entails integration of two or more MS models. In other words, to come-up with a more robust SDM model, one will have to use a combination of models. These models could be exclusive borrowed from MS; from MS and other inter-disciplinary subject; or exclusively from other inter-disciplinary subject.

iii. The role of supporting negotiations: Over the last three to four decades, there has been an emergence of a new branch in MS known as the soft MS. Such problem structuring methods have aided the management of messy complex problems, and as Franco (2011) argues, "SDM is one of the messiest tasks experienced by organizations”.

iv. Managing complexity: SDM process is sometimes complex and decisions could be nerve-racking. This managing of complexity blends very well with soft MS techniques. Examples of such techniques include soft systems methodology by Checkland (1981), interactive planning by Ackoff (1979), robustness analysis by Rosenhead (1980), strategic choice approach by Friend and Hicklings (1987), viable systems model by Beer (1985), among others.

v. A focus on practicality: One of the major strengths MS has to offer is its focus on practicality that differentiates from the strategic research that has theoretical bias. Whilst undoubtedly good theoretical thinking is important, focusing attention solely on this provides managers with little help in the practice of SDM.

\section{Relationship between MS, SDM, and MSMEs}

There are many similarities between MS and SDM; for instance, Franco (2011) noted that MS emerged during post-World War II, so too was the field of strategy, strategic management, and strategic planning. Many studies in SDM describe the process as a sequence of steps, phases or routes (e.g. Fredrickson, 1984; Mintzberg, Raisinghani \& Theoret, 1976). This closely mirrors the MS phase process that also dissects the components of the decision into logical steps before arriving at a sound (or optimal) decision. However, for simplicity, a mirror of the sequential generic DM process (borrowed from Brim, Glass, Lavin, \& Goodman, 1962; Dewey, 1910; Simon, 1960) is compared to that of the classical MS process as shown in Figure 1 (Hillier \& Liebermann, 2004). As can be seen from the figure, the two processes are conceptually similar except for the mathematical model that is required in MS process but substituted with "analyze the situation" and "develop options" phases in the case of DM (or SDM).

Management Science (MS) has had a profound impact in the transformation of many 
organizations with its modeling tools that depict a simplified version of reality. There are many success stories across the globe on the decades of successful implementation of MS tools and its visualization. For example, INFORMS (2012) through its Science of Better campaign has developed an extensive list of the success stories classified by industry type, function and benefit. Although a wide range of modeling applications exists for large enterprises, this does not come as a surprise because of the high financial stake involved. However, it is arguable that, in spite of the MSMEs having relatively small-scale operation, the mathematical modeling structure does not change. That is, the same model that handles a large-scale problem is applicable to solve smaller version of the problem encountered by MSMEs. For example, Monelos, Sánchez, and López (2012) have used three mathematical models: discriminant analysis, logit, and linear multivariate regression in non-financial Galician SMEs. Similarly, Ali and Xie (2011) have used a simulation model in implementing an Enterprise Resource Planning within SMEs. Moro and Nolte (2012) decomposed investor's risk into a cluster risk (cluster survival rate) and a firm specific risk (historical un-success of the investor) that were related by a markov transition probability matrix modeled with a logit and estimated with maximum-likelihood.

This is also true for SDM where the focus has been on big corporations and less attention paid on MSMEs. Kraus, Sebastian, and Reschke (2008) notes that, "the present research on strategic planning in SMEs is still in its infancy and reveals an insufficient level of differentiation both concerning relevant enterprise characteristics as well as compared to research on larger firms”.

Whereas strategic management is long-term in nature (over three years), MSMEs life span is much shorter, an argument that is used by other researchers to justify its irrelevance to SDM. According to Kraus et al. (2008) there are three major objections expressed by this school of thought against the use of strategic processes in SMEs:

i. Strategic instruments limit the flexibility and the ability for improvisation.

ii. It is preferable to use the limited time resources for operational, sales or R\&D activities rather than for strategy development processes.

iii. Strategic management is too bureaucratic.

Kraus et al. (2008) detest the above propositions and give three reasons to justify the natural orientation of SDM on SMEs. First, SMEs adopt a niche strategy that focuses on specialized markets where large corporation normally ignores. Second, given their limited resources, they normally concentrate on a small product range where strong competitive advantages and specific problem-solving competencies build up, for example, with regard to qualitative market leadership. Finally, the high decision flexibility and direct customer contacts means that research and development findings easily convert into marketable innovations. However, over-dependency on a few products remains risky and cannot compensate. In summary, after a detail literature review, they concluded that “decision-makers of SMEs also apply planning, although in many cases rather intuitively and/or informally". 


\section{SDM Process}

Elbanna and Child (2007) notes that strategic decision-making process (SDMP) deals with the process of making the strategic decision, implementation and the factors that affect the process. A more elaborate definition pegs SDM as concerning with issues such as the design and planning strategies of the organization, initiatives for mergers and acquisitions, large investments in new products or markets, required disinvestments, make or buy options and internal reorganizations (Cray et al., 1988, 1991; Dean \& Sharfman, 1996; Nutt, 1999).

There is no doubt that SDM is emerging as one of the most vibrant areas of contemporary research in strategic management. Citroen (2009, p.20) notes that Mintzberg, Raisinghani, and Theoret (1976) concur to this considerable wide interest as “...quite divergent: subjective or objective, prescriptive or descriptive, based on experience or exploratory, reverting to economics, psychology, political science, anthropology or political sociology. All these viewpoints have successively had their advocates and thus have been the objects of research and subsequent publications." The discipline has strong roots in decision science with borrowings from behavioral decision theory. Schwenk (1995) observes that it has now gained its own momentum. Early work on SDM can be traced from Cyert and March (1993, 2002), Eisenhardt and Zbaracki (1992), Frederickson (1984), Mintzberg et al. (1976), Nutt (2005), Papadakis and Barwise (1998b), Simon (1947, 1957, 1979), and Weirich (2004).

The classical views of SDM processes were based on normative or descriptive studies and on assumptions most of which remain untested (e.g. Bateman \& Zeithaml, 1989; Langley 1990; Rejagopalan et al. 1993, 1997; Schneider \& DeMeyer, 1991). These views are upheld by Eisenhardt and Zbaracki (1992) who notes that despite the crucial role of strategic decisions, the strategy process research has not departed significantly from a stage of being based on “mature paradigms and incomplete assumptions” (Eisenhardt and Zbaracki, 1992, pp.17). Papadakis and Barwise (1998b) give four reasons for the limitations of existing research on the context and the process of SDs. First, there has been little research on the influence of broader context on SDM. Second, although there are many attempts to come-up with SDM models, most of these have been underspecified. Third, although SDM is multidimensional, most of the research confines to one attribute (e.g. comprehensiveness, decentralization, politics, etc). Finally, most of the research findings are contradictory to warrant establishment of a coherent theory.

Notwithstanding, the classical views is still challengeable. For instance, researchers have long established strategic analytical tools that keep adjusting an organization to its constantly changing environment. These include Porter's (2008) five forces competitive model, Johnson and Scholes's (1993) strategic analysis, choice and implementation model, and Kaplan and Norton's (1993) balance scorecard concept. The acceptance of the immaturity paradigm view implies the operationalization of the SDM process has not commenced. However, this contradicts the numerous SDM models (refer to section 5) that have successfully been deployed. 


\section{SDM Theories}

The theories underpinning SDM are somewhat eclectic that demand multidisciplinary approach and appears non-differential from DM theories. This does not come as a surprise because, in any case, DM is not only the bedrock science of SDM but most of the DM theories are strategic in nature. There is no universal agreement on a standardized classification on the theories. One view pegs the criteria on the number of people undertaking the decision. Thus, we can have single SDM theories and according to Brown (2005), group SDM theories. Brown relates the group theory in the context of the board and organizational performance where there are several actors and forums for channeling questions and devising solution (a phenomenon coined as garbage-can theory). Cohen, March, and Olsen (1972) observed that organization has four independent streams (i.e. problems, solutions, participants, and choice opportunities) that flow in and out of a garbage can, and which problems get attached to solutions is largely due to chance.

Many researchers have also classified the theories as either rational or non-rational (Gigerenezer, 2001; Hansson, 2005; Oliveira, 2007). In differentiating the two, Gigerenezer (2001) identified four attributes for rational theories as: Optimization, normative, omniscience and internal consistency. In the same vein, non-rational theories are identifiable to posses attributes such as non-optimization, descriptive, search, ecological rationality and cognitive building blocks like emotions, imitation, and social norms. Table 1 depicts the differences between rational and non-rational theories using Gigerenezer's classification. This differential approach originates from psychology and is not popular for two main reasons. Some theories may possess two or more attributes and are not classifiable using a single attribute. Further, the fact that this classification originates from psychology, leads to a tendency of disassociation from other disciplines. Nevertheless, the classification approaches is not as crucial as the identification of the theories that have proven to be a success. Some of the theories that have gained popularity in the context of SDM are as follows.

\subsection{Subjective Expected Utility (SEU) Theory}

Savage (1954) developed the axiomatic subjective expected utility (SEU) theory in which a decision maker chooses between alternatives (or strategies) in the presence of risk. Savage capitalized on the assumption that the decision maker will always tend to seek pleasure and avoid pain and as such, he will make the following computations:

i) Subjective utility that accounts on the individuals judged weightings of utility, rather than on objective criteria.

ii) Subjective probability that accounts on the individuals estimates of likelihood, rather than on objective statistical computations.

Suppose an uncertain event has possible outcomes $\left\{x_{i}\right\}$ each with a utility, $\mathrm{u}\left(x_{i}\right)$, then the choices can be explained as arising from a function in which there is a subjective probability of $\mathrm{P}\left(x_{i}\right)$ for each outcome. Thus, the subjective expected utility is the expected value of the 
utility given as:

$$
\sum_{i} u_{i}\left(x_{i}\right) P\left(x_{i}\right)
$$

The strategy (or alternative) that maximizes the above function would be the preferred choice. The theory lays its foundation on the four tenets of rational preferences: transitivity, monotonicity of consequences, independence of a common consequence, and accounting equivalences (for a detail description of the tenets, refer to Luce, 1999):

i) Transitivity: if $\mathrm{X}$ is preferred to $\mathrm{Y}$ and $\mathrm{Y}$ is preferred to $\mathrm{Z}$ then $\mathrm{X}$ is preferred to $\mathrm{Z}$.

ii) Monotonicity: either more of an attribute is preferred, or less of an attribute is preferred.

iii) Preference independence: an attribute $\mathrm{Y}$ is preferentially independent of attribute $\mathrm{X}$ if preferences for specific outcomes of Y do not depend on the level of the attribute X.

iv) Accounting equivalence: if two alternatives occur under identical conditions (ignoring the order of events occurrence) then they are indifferent.

This theory has not been popular for two main reasons. First, the theory is based on the assumption that the decision maker will seek to reach well-reasoned decisions based on consideration of all possible known alternatives i.e., decision maker is always rational. However, human decision-making is more complex and can be irrational. Furthermore, Slovic and Tversky (1974) demonstrated that people do not believe in Savage axioms. In particular, through empirical evidence, Luce (1992) proved that the axioms of transitivity and monotonicity do not hold. Larichev (1999) concur to the earlier views and cites the difficulties of checking axioms as the main hindrance in the application of the theory.

\subsection{Prospect Theory}

To overcome the inherent limitations of the SEU theory, Kahneman and Tversky (1979) complemented it with the theory of choice that accurately describes how people actually go about making their decisions. The theory predicts that decision makers tend to be risk averse in a domain of gains (or when there is a favorable anticipation). Similarly, the decision maker is relatively risk seeking in a domain of losses. In other words, they established that people aspire for uniqueness in relation to prospects being considered and will tend to shy away from the components shared by all. They also discovered that people lean more towards the outcomes obtained with certainty than those obtained by mere probabilities.

Kahneman and Tversky (1979) introduced two stages in the decision process. In the first stage, the editing phase, there is identification and definition of gains and losses relative to some neutral reference point. In the second stage, known as the evaluation phase, the options get evaluated using two scales. One of these replaces the monetary outcome given in the problem, whereas the other replaces the objective probabilities given in the problem (Hansson, 2005). In its simplest form, the formula given by Kahneman and Tversky for the 
evaluation phase is as follows:

$U=\sum_{i} w\left(p_{i}\right) v\left(x_{i}\right)$

Where $U$ is the overall or expected utility of the outcomes to the individual making the decision, $x_{1}, x_{2} \ldots$ are the potential outcomes and $p_{1}, p_{2} \ldots$ their respective probabilities. The value function, $v$, assigns a value to an outcome.

Figure 2 that is taken from Kahneman and Tversky (1979, p. 202), depicts a value function in prospect theory. The curve is normally concave for gains (implying risk aversion), commonly convex for losses (risk seeking), and is generally steeper for losses than for gains (loss aversion). Figure 3 that is also taken from Tversky and Kahneman (1986, p. 264) shows the decision weight as a function of probabilities. Decision weights are generally lower than the corresponding probabilities, except in the range of low probabilities.

Although the prospect theory overcomes the paradox of choice stemming from SEU theory, it still has a number of limitations. A solution of the problems of choice depends on the framing and this introduces some biasness. Similarly, the natural desire to round the probabilities could lead to conflicting results. Furthermore, just like SEU theory, the prospect theory is axiomatic basis that could pose a challenge during validation. When reference points are changed, the same vague conclusions might stimulate different perceptions of gains or losses. Consequently, because of these dissimilar perceptions, choices might be more difficult to predict (Larichev, 1999; Oliveira, 2007).

\subsection{Satisficing Theory}

Simon (1957) advanced the concept of bounded rationality where the decision-maker has limited information, time and intellectual ability to make a decision. Instead, the decision-maker work with limited and simplified knowledge, to reach acceptable, compromise choices ('satisficing'), rather than pursue 'maximizing' or 'optimizing' strategies in which one particular objective is fully achieved (Marshall, 1998). The word "satisficing" goes contrary to the notion of optimization. According to Simon, optimization does not exist in real world; instead, we have 'good enough' alternatives. Williams (2002, p.15) contrasts the concept of bounded rationality to that of the rational decision-making (refer to Table 2).

The search for the best solution may be indefinite and one will not wait for eternity hoping to find a solution that just fits and completely covers all the areas. It establishes that the more information searched, the higher is the collection cost; but cost minimization is limited up to the point of discovery of a compromise (answer to the challenge). For example, consider one looking for where to get and buy a sofa set. Many sellers exist in the market but a buyer (i.e. decision maker) will not travel all over the large market enquiring about price and quality. He would rather enquire from the first five sellers and then settle on one he views to be offering an acceptable product at his accepted price. The cost for searching the whole market for a 
better quality and a fair price item would raise the cost of obtaining the same. The time required for the entire exercise might also be lacking. The theory, therefore, asserts a general proposition that decision makers are better off when they accept the compromise solution than searching indefinitely for what one may term the 'best' solution.

This theory is in contrast to the SEU theory where all the available choices are assigned utilities and probabilities. In this theory, the standards and parameters to be met for a problem of choice are set, and then the first solution that comes along and that emanates the qualities as detailed by the parameters is selected. This implies that in the search for quality furniture for a given price, the decision maker sets the desired quality and the maximum amount he is willing to pay. The search, thus, concludes the moment a combination of the two integrates. According to Marshall (1998), the application of the satisficing models has been useful in the theory of the firm and corporate behaviour. For instance, to maximize its profits a firm needs complete information about its costs and revenues, which is not readily available until the completion of an event (e.g. financial year).

\subsection{Attribution Theory}

The word "attribution" literally means the grant of responsibility and tries to explain the behavior attributed to a person or situation. Heider (1958) advances the theory concerned with how people perceived the behavior of themselves and other people. Heider (1958) initiated the theory, later Weiner and colleagues (e.g., Jones et al., 1972; Weiner, 1974) developed a theoretical framework that has become a major research paradigm of social psychology. Heider divided the behavior attribute into internal and external factors. Internal attribution describes the behavior within a person and factors attributes like character, attitude, aptitude and personality. In the case of external attribution, the situation gets assign to cause of a particular behavior e.g. the assignment of environment or weather to causality.

Weiner (1974) advances a three-stage process that underlies an attribution. (i) The person must perceive or observe the behavior. (ii) Then the person must believe that the behavior was intentionally performed, and (iii) the person must determine if they believe the other person was forced to perform the behavior (in which case the cause is attributed to the situation) or not (in which case the cause is attributed to the other person). Weiner confined the theory on the most important factors affecting the attribution for achievement such as ability, effort, task difficulty, and luck. Weiner also classified attribution along three causal dimensions: locus of control, stability, and controllability. The locus of control further differentiates into either internal or external. The stability dimension analyses whether there are changes over time attributed to causes. For example, we can have ability that is stable and internal; or an effort that is unstable and internal. Controllability is in reference to the causes one is able to control (e.g. skill/efficacy), and from causes one cannot control (e.g. aptitude, mood, other's actions, and luck). In summary, the main underlying principles of the theory include:

i) Attribution is a three-stage process: (1) Observation of behavior, (2) behavior is 
determined to be deliberate, and (3) attribution of behavior to be internal or external causes.

ii) Attribution of achievement to (1) effort, (2) ability, (3) level of task difficulty, or (4) luck.

iii) Causal dimensions of behavior are (1) locus of control, (2) stability, and (3) controllability.

\subsection{Multi-attribute Utility Theory (MAUT)}

The next stage in the evolution of utility theories (after SEU and prospect theories) is the multi-attribute utility theory (MAUT) accredited to Keeney and Raiffa (1976). Unlike the previous theories, MAUT involved aggregation of several single attribute utilities. The computations of the MAUT function are as follows (Suslick \& Furtado, 2001):

i) Identification of significant design attributes and generation of alternative designs.

ii) Verification of relevant attribute conditions or bounds.

iii) Use of probability to determine the decision-makers preference.

iv) Evaluation of Single Attribute Utility (SAU) function and trade-off preferences.

v) Combining SAUs into Multi-Attribute Utility function (MAU).

vi) Selection of the alternative with the highest MAU value by ranking the alternatives.

Initially the selection of decision maker's preference to the attributes is undertaken. The selected attributes should be meaningful, simple, non-redundant, and reflect important aspects of the decision. Thereafter, upper and lower bounds for each attribute are specified using mathematical optimization technique or any other rule. In the third step, determination of the probabilities, one can select $\mathrm{p}$ as the probability of the most preferred alternative or 1-p of the least preferred alternative. The indifference between the two choices is the certainty equivalence. Based on certainty equivalence, the development of SAU functions is undertaken using a set of decision-makers preferences. The best outcome is set at one and the worst at zero; the SAU function describes decision-makers compromise between the best and worst alternatives.

The next step in the MAUT process involves the aggregation of SAU functions. The additive and multiplicative forms are the common for MAUT models. The general form of the additive model is:

$u(x)=\sum_{i=1}^{m} k_{i} u_{i}\left(x_{i}\right)$

Where $i$ is the attribute of interest; $x_{i}$ is the evaluation unit for attribute $i$; $u_{i}$ is the decision-makers preference for ${ }_{\mathrm{x}}$; and $k$ is the relative importance of attribute $i$, for the $n$ 
attributes, such that $\sum_{i=1}^{n} k_{i}=1$.

The higher the multi-attribute utility measure, $u(x)$, the more desirable is the alternative. Thus, the magnitude of the utilities for each alternative establishes a ranking system that indicates the decision maker's preferences for the alternatives. The utility values associated with an alternative directly relates to the objectives originally chosen to guide the decision and reflect the degree of achievement of those objectives. The additive model is relevant if the decision maker's preference satisfy the additive independence. However, the usage of multiplicative form is conditional if and only if preferential independence and utility independence conditions are satisfied. The representation of multiplicative model is as follows:

$1+k u(x)=\prod_{i=1}^{n}\left(1+k k_{i} u_{i}\left(x_{i}\right)\right)$

Where $0 \leqslant k_{i} \leqslant 1$ is the scaling constant (weight) for the $\mathrm{n}$ attributes where $\sum_{i=1}^{n} k_{t} \neq 1$; and $\mathrm{k}$ is the additional scaling constant such that

$1+k=\prod_{i=1}^{\mathrm{m}}\left[1+k k_{i}\right]=1$

\section{SDM Models}

Models are the application or the outcome of theories. They represent a physical theory or a projection of an underlying theory. When scientists perform a procedure for a scientific purpose, the experimental design requires models. Models give basis and structure in the formulation of theories. Using the theoretical base, models serve as the representation of possibilities. Given the theories, researchers can create simulations and state hypotheses modeled after the theories. In some cases, confirmation of theory requires a model. They serve as the variable for experiments needed for the testing of the theory's correctness. According to Celine (2013), theories and models are distinct and are as follows:

i) Models and theories provide possible explanations for natural phenomena.

ii) Models can serve as the structure for the systematic formulation of a theory.

iii) Theories can be the basis of creating a model that shows the possibilities of subjects observed.

iv) Models are physical tool that verifies the theories.

There are numerous models in SDM that classified as either sequential or non-sequential. 
These include the classical decision-making process by Dewey (1910), the general model by Mintzberg et al. (1976), Cynefin framework by Kurtz and Snowden (2003), and more recently, MCDA for SDM by Montibeller and Franco (2010), among others. In this section, the selected models will be discussed with particular emphasis on MCDA for SDM as the model of choice for the research as applied by Ahmed, Bwisa and Otieno (2012).

\subsection{The Classical Decision-Making Process}

Nichols (2005) and Li (2008) gives a critique of the "classic" decision making process that is sequential and based on the rationality assumptions. The model (refer to Figure 4) assumes certainty conditions surrounding the decision-making framework that traverses through three main activities: intelligence activity, design activity and choice activity. Hucaynski and Buchanan (2002, p.740) have equated the rationality concept with "scientific reasoning, empiricism and positivism and with the use of decision criteria of evidence, logical arguments and reasoning". This model is the cradle of the rational-analytic approach to SDM and with minor variations, appears in many places.

The classical method is simple, easy to understand and appeals to the belief in rationality. It is also widely known and managers are comfortable with it. However, it does not reflect the reality of SDM situations since it assumes the causal linkages are knowable and known. Robbins and Coulter (2003) observed that it does not represent how people make decisions in the organization. Nichols (2005, p.3) adds, "it does not reflect the iterative nature of developing clarity, formulating a viable course of action and developing commitment to that course of action”. In addition, according to Nichols, it does not reflect the political aspects of SDM, and it ignores intuition or "gut" instinct.

\subsection{The Military Model}

According to Nichols (2005), the military model shown in Figure 5 belongs to the U. S. Army War College and is a variation of the classic model. The military model is sequential and starts with information mission where the organization sets the goals and objectives of the SDM problem. The development of alternatives follows suit with evaluation made and subsequently choosing the best alternative. Eventually, the best alternative is implemented before ultimately trailing the information user reaction (i.e. command, lead and manage). The outline step depicts the iterative nature of decision-making using feedback loops mechanism and is one of the main advantages attributed to this model. Similarly, the model dictates the organizational goals and objectives as a driving force in decision-making. Finally, the model emphasizes the importance of execution or following through to make the decision happen.

Unfortunately, this model encounters the same limitations as the classic model; it is static, unrealistic and does not accommodate the dynamism of the problem situation. The model also ignores other aspects of decision-making, such as, politics, intuition, consensus and the ability to spot pattern within the decision-making framework.

\subsection{Mintzberg’s General Model of the Strategic Decision Process}


Mintzberg et al. (1976) proposed a sequential three phase model (refer to Figure 6) with subroutines that suggested a notion of critical element in decision-making. Previous research tended to be "window dressing" where the focus was more on decisions as choices made from alternatives. To overcome this fallacy, their proposed model consisted of the identification phase, the development phase, and the selection phase. In the identification phase, opportunities, problems and crises arising from inside and outside of the organization are recognized and identified, which invokes decisional activity. Then different types of search, modification, or design behaviors are involved in the development phase to find alternatives for the situation. The final phase of selection narrows down on ready-made alternatives and selects one based on the evaluations of a few feasible ones. Eventually, it ratifies the chosen one for action.

Nichols (2005) outlines five main advantages of this model: First, it defines decision as a commitment to a course of action instead of simply a choice from among alternatives. Second, it draws attention to many key aspects of SDM with three phases (identification, development, selection) and seven routines (recognition, diagnosis, search, design, screen, evaluation-choice, authorization). Third, unlike the classical model, it factors in the dynamics of the decision-making process with respect to: interrupts, timing delays and speed-ups, feedback delays, comprehension cycles and failure recycles.

Fourth, it highlights the importance of decision control, decision communication and political supporting routines: planning, switching, exploration, investigation, dissemination, bargaining, persuasion and co-optation. Finally, the research suggests seven useful patterns of strategic decisions: simple impasse, political design, basic search, modified search, basic design, blocked design, dynamic design. The three main disadvantages of this is that, one, it is complicated and many practitioners cannot understand. Second, it is contextual and applicable in an organizational setting i.e., it might not be relevant to individual or personal decision-making scenario. Finally, Nichols (2005) observes that it provides little in the way of procedural guidance.

\subsection{The Cynefin Framework}

A more innovative non-sequential SDM model carries the Welsh name Cynefin or habitat. Developed by Kurtz and Snowden (2003), Cynefin means an evolutionary perspective of complex systems characterized with uncertainty. It draws on research from various disciplines ranging from complex adaptive systems theory and cognitive science through to anthropology and evolutionary psychology. As Kurtz and Snowden (2003, p.470) remarked, it is concerned with "how people perceive and make sense of situations in order to make decisions”. The framework suggests four basic approaches to SDM based on the characteristics of the situation at hand (see Figure 7). Unlike the business matrices, there is no preference of one quadrant over the other. The central represents the "unknown" or "disorder" domain and remains open. The objective of the framework is to reach consensus that reduces the unknown domain. The summarizations of the four quadrants are as follows: 
i) Complex: Probe to clarify patterns; sense the patterns; respond by stabilizing desired patterns (manage the out there).

ii) Complicated: Sense incoming data; analyze that data; respond in accordance with expert advice or based on the analysis (respond to the out there).

iii) Chaotic: Act quickly and decisively; sense reactions to that action; respond further as appropriate (feel your way along).

iv) Simple: Sense incoming data; categorize it in accordance with known schema; respond with predetermined practices.

The Cynefin framework has a number of advantages: (i) It is a good fit with the kinds of situations strategic decision makers face. (ii) It reflects current management and organizational theory, thinking and practice. (iii) It challenges some basic assumptions, such as, the world is in order and known or knowable, people are always and completely rational, and actions always point to underlying intent and never reflect happenstance (Nichols, 2005).

\subsection{MCDA for SDM}

MCDA is a model that deals with decision problems under the presence of multiple, usually conflicting criteria. MCDA follows a set of procedures that analyze complex decisions based on distinct, conflicting criteria and by deriving scores provide an overall ordering of options, from the most preferred to the least preferred option. MCDA consists of a series of techniques (i.e., weighted summation, concordance, analysis, etc.) that facilitate the scoring, ranking, or weighting of decision-making criteria based on stakeholder preferences. These techniques ideally operate within a transparent framework that encourages informed decision-making by providing opportunities for genuine, substantive participation in decision-making. The best available scientific knowledge supports the framework that can also incorporate uncertainties in an honest, rigorous and consistent manner (Suedel et al., 2011).

Montibeller and Franco (2010) initially proposed the use of MCDA for SDM and pioneered its implementation in the context of strategy workshops and later within organizations (Montibeller \& Franco, 2011). Similarly, Ram, Montibeller and Morton (2011) proposed a six-step framework (Figure 8) that used MCDA in the evaluation of strategic options.

Likewise, Mutikanga et al. (2001) presented an integrated multi-criteria decision-aiding framework for strategic planning of water loss management. Using one of the MCDA techniques (i.e. PROMETHEE II), the prioritization of the diverse water loss reduction options for Kampala city in Uganda was done.

MCDA typically involves the following steps (Communities and Local Government, 2009):

i) Establish the decision context: Establish aims of the MCDA, and identify decision maker(s) and other key players.

ii) Identify the options to appraise and inputting all the available options. 
iii) Identify objectives and criteria: Identify criteria for assessing the consequences of each option.

iv) Scoring: Assess the expected performance of each option against the criteria. Then assess the value associated with the consequences of each option for each criterion. Describe the consequences of the options; score the options on the criteria; and check the consistency of the scores on each criterion.

v) Weighting: Assign weights for each of the criterion to reflect their relative importance to the decision.

vi) Combine the weights and scores for each option to derive an overall value: Calculate overall weighted scores at each level in the hierarchy; calculate overall weighted scores.

vii) Examine the results.

viii)Sensitivity analysis: Conduct a sensitivity analysis: do other preferences or weights affect the overall ordering of the options? Look at the advantage and disadvantages of selected options, and compare pairs of options. Create possible new options that might be better than the original. Repeat the above steps until a 'requisite' model is obtainable.

In MCDA, the alternatives have scores based on stipulated criteria normally on an interval or ratio scales. Thereafter, assignments of weights to the criteria and computation with an appropriate algorithm follows suit. This accounts on value or utility functions, goal programming, outranking or descriptive/multivariate statistical methods to determine the rank of the alternatives. One of the greatest challenges associated with MCDA is how to compare and combine dissimilar metrics. Often dissimilar criteria undergo transformation or normalization to a single scale such as zero to one. Transformation to this commensurable scale is accomplishable through multiple techniques. Following scale transformation, the combination of criteria and value through aggregation algorithms is undertaken. Consequently, the comparison of alternatives and ranking is obtainable (Suedel et al., 2011).

The multi-criteria analysis problem divides into three types: problems of multi-criteria choice, problems of multi-criteria ranking and problems of multi-criteria sorting (Vassilev, Genova, \& Vassileva, 2005). The problem of choice essentially entails finding the relevant MCDA technique among the various methods in use or in literature. This also breeds the classification problem where there is no universal agreement on a standard approach.

According to Vincke (1992) the methods can be grouped into three separate classes; the multi-attribute utility, (value) theory methods, outranking methods and interactive algorithms. An alternate way of classification is according to the number of individuals involved in the decision-making process. Hence, there are single decision maker methods and group decision-making methods. Yet another classification distinguishes deterministic, stochastic and fuzzy methods (Mateu, 2002). In the deterministic approach, the decision-making problem (i.e. the alternatives, criteria, etc.) are known with certainty and definite. The stochastic or probabilistic case corresponds to uncertainty surrounding the decision-making 
problem e.g. the criteria are random variables. Finally, fuzzy methods consider different types of uncertainty and imprecision in some of the elements of the decision making problem.

\section{Conclusion}

In this paper, we traced the origin of SDM and gave some conclusive evidence that the disciplined has reached maturity. Numerous SDM models backed-up with relevant theories reveal that the SDM process is recursive; it keeps looping around instead of simply unfolding in a linear fashion. Consequently, this call for a hybrid approaches in tackling SDM problems where the use of both rational and non-rational methods addresses the problem. In particular, analytical ways of solving SDM problems (such as the use of MCDA) have gained popularity with immense impact in shaping the discipline.

The SDM process cuts across disciplines with wide application in various sectors of the economy. In large corporations, where strategic decisions are ambiguous and uncertain; the use of SDM techniques is indispensable. Similarly, for MSMEs, numerous SDM techniques are in use in business planning but rather intuitively and/or informally.

\section{Acknowledgment}

This research was supported by NATIONAL COUNCIL FOR SCIENCE AND TECHNOLOGY grant under the contract number NCST/ST\&I/RCD/4 ${ }^{\text {th }}$ Call PhD/002 ST\&I Grant Fund.

\section{References}

Ackoff, L. (1979). Resurrecting the future of operational research. Journal of the Operational Research Society, 30(3), 189-199. http://dx.doi.org/10.1057/jors.1979.41

Ahmed, A.H., Bwisa, H. M., \& Otieno, R.O (2012). The Strategic Kenyan Business Selection Tool for MSMEs. International Journal of Business and Management Tomorrow, 2(12), 1-11.

Ali, M., \& Xie, Y. (2011). A decision support system for ERP systems implementation in small medium enetrprises (SMEs). International Conference, CENTERIS. Algarve, Portugal. http://dx.doi.org/10.1007/978-3-642-24358-5_31

Arsham, H. (2010). Leadership decision making. Retrieved February 23, 2012, from http://home.ubalt.edu/ntsbarsh/oper640

Bailey, G. (2007). The concept of strategy as understood in the fields of military planning and business management. Retrieved February 27, 2013, from http://bef-battles.org.uk/pdf/methodology_2.pdf

Bateman, S., \& Zeithaml, P. (1989). The psychological context of strategic decisions: A model and convergent experimental findings. Strategic Management Journal, 10(1), 59-74. http://dx.doi.org/10.1002/smj.4250100106

Beer, S. (1985). Diagnosing the system. Chichester: John Wiley and Sons. 
Brim, G., Glass, D., Lavin, D., \& Goodman, N. (1962). Personality and decision processes. Stanford: Stanford University Press.

Brown, W. A. (2005). Exploring the association between board and organizational performance in nonprofit organizations. Nonprofit Management and Leadership, 15(3), 317-339. http://dx.doi.org/10.1002/nml.71

Celine, C. (2011). Difference between models and theories. Retrieved March 15, 2013, from DifferenceBetween.Net: http://www.differencebetween.net/

Checkland, B. (1981). System thinking, systems practice. Chichester: John Wileys and Sons.

Citroen, L. (2009). Strategic decision making process: The role of information. Doctoral Thesis: University of Twente. Retrieved October 15, 2012, from http://doc.utwente.nl/61222/1/thesis_C__Citroen.pdf

Cohen, M., March, J., \& Olsen, J. (1972). A garbage can model of organizational choice. Administrative Science Quarterly, 17(1), 1-25. http://dx.doi.org/10.2307/2392088

Communities and Local Government. (2009). Mutli-criteria analysis: a manual. Retrieved from http://www.communities.gov.uk

Cray, D., Mallory, R., Butler, J. H., \& Wilson, C. (1998). Sporadic, fluid and constricted processes: Three types of strategic decision making in organizations. Journal of Management Studies, 25(1), 13-39. http://dx.doi.org/10.1111/j.1467-6486.1988.tb00020.x

Cyert, M., \& March, G. (1993). A behavioral theory of the firm. Malden: Blackwell Publishers.

Cyert, M., \& March, G. (2002). A summary of basic concepts in the behavioral theory of the firm. In G. Salaman, Decision making for business: A reader. London: Sage Publications.

Dean, W., \& Sharfman, P. (1996). Does decision process matter? A study of strategic decision-making effectiveness. The Academy of Management Journal, 39(2), 368-396. http://dx.doi.org/10.2307/256784

Dewey. (1910). How we think. New York: Dover.

Eisenhardt, M., \& Zbaracki, J. (1992). Strategic decision-making. Strategic Management Journal of Management Studies, 13(Special Issue), 17-37. http://dx.doi.org/10.1002/smj.4250130904

Elbanna, S., \& Child, J. (2007). The influence of decision, environmental and firm characteristics on the rationality of strategic decision-making. Journal of Management Studies, 44(4), 561-591. http://dx.doi.org/10.1111/j.1467-6486.2006.00670.x

Franco, A. (2011). How OR can contribute to strategy making. Journal of Operational Research Society, 62(5), 921-932. http://dx.doi.org/10.1057/jors.2010.128 
Fredrickson, J. (1984). The comprehensiveness of strategic decision process: Extension, observation, future directions. The Academy of Management Journal, 27(3), 445-466. http://dx.doi.org/10.2307/256039

Friend, K., \& Hicklings, A. (1987). Planning under pressure. Chichester: John Wiley and Sons.

Gigerenzer, G. (2001). Decision making: Non-rational theories. In N. J. Smelser, \& B. P. Baltes, International Encyclopedia of the Social and Behavioral Sciences (Vol. 5, pp. 3304-3309). Oxford: Elsevier.

Hansson, S. (2005). Decision theory: A brief introduction. Stockholm: Royal Institute of Technology.

Heider, F. (1958). The psychology of interpersonal relations. New Jersey: Lawrence Erlbaum.

Hillier, F., \& Liebermann, G. (2009). Introduction to operations research (9th ed.). New York: McGraw-Hill.

Huczynski, A., \& Buchanan, D. (2001). Organizational behaviour: An introduction. Harlow: Financial Times / Prentice Hall.

INFORMS. (2012). Operations research: The science of better. Retrieved July 20, 2012, from http://www.scienceofbetter.org

Johnson, G., \& Scholes, K. (1993). Exploring corporate strategy. Hertfordshire: Prentice Hall Europe.

Jones, E., Kannouse, E., Kelley, H., Nisbett, E., Valins, S., \& Weiner, B. (1972). Attribution: Perceiving the causes of behavior. New Jersey: General Learning Press.

Kahnmean, D., \& Traversky, A. (1979). Prospect theory: An analysis of decision under risk. Econometrica, 47(2), 263-292. http://dx.doi.org/10.2307/1914185

Kaplan, S., \& Norton, P. (1992). The balance scorecard - measures that drive performance. Havard Business Review, 70(1), 71-79.

Keeney, R., \& Raiffa, H. (1976). Decisions with multiple objectives: Preferences and value tradeoffs. New York: Wiley.

Kraus, S., Sebastian, B., \& Reschke, C. (2008). Implications of strategic planning in SMEs for international entrepreneurship research and practice. In M. Terziovski, Energizing management through innovation and entreneurship (pp. 110-127). Lonodon: Routledge.

Kurtz, C., \& Snowden, D. (2003). The new dynamics of strategy. IBM Systems Journal, 42(3), 462-483. http://dx.doi.org/10.1147/sj.423.0462

Langley, A. (1990). Patterns in the use of formal analysis in strategic decisions. Organizational Studies, 11(1), 17-45. http://dx.doi.org/10.1177/017084069001100104 
Larichev, O. (1999). Normative and decsriptive aspects of decision making. In T. Gal, T. Stewart, \& T. Hanne, Multicriteria decision making: Advances in MCDM models, algorithms, theory and application (pp. 5.1-5.24). Boston: Kluwer Academic Publishers.

Li, B. (2008). The classical model of decision making has been accepted as not providing an accurate account of how people typically make decisions. International Journal of Business and Management, 3(6), 151-154.

Luce, R. (1992). Where does subjective expected utility fail descriptively? Journal of Risk and Uncertainty, 5(1), 5-27. http://dx.doi.org/10.1007/BF00208784

Marshall, G. (1998). "Satisficing". A dictionary of sociology. Retrieved March 12, 1998, from http://www.encyclopedia.com/doc/1088-satisficing.html

Mateu, A. (2002). ClusDM: A multiple criteria decision making method for heterogeneous data sets. Doctoral thesis, Polytechnic University of Catalonia. Retrieved from http://www.tesisenred.net/bitstream/handle/10803/6638/01CAPITOL_2.pdf

Mintzberg, H., \& Lampel, J. (1999). Reflecting on the strategy process. Sloan Management Review, 40(3), 21-30.

Mintzberg, H., Raisinghani, D., \& Theoret, A. (1976). The stucture of unstructure decision processes. Administrative Science Quarterly, 21(2), 246-275. http://dx.doi.org/10.2307/2392045

Monelos, P., Sanchez, C., \& Lopez, M. (2012). A model to forecast financial failure in non-financial Galician SMEs. Retrieved July 8, 2012, from University of Coruna: http://repositorio.ipl.pt/bitstream/10400.21/1421/1/25.pdf

Montibeller, G., \& Franco, A. (2010). Multi-criteria decision analysis for strategic decision making. In C. Zopoundis, \& P. M. Pardalos, Handbook of multicriteria analysis (pp. 25-48). Berlin Heidelberg: Springer-Verlag. http://dx.doi.org/10.1007/978-3-540-928287-0

Montibeller, G., \& Franco, A. (2011). Raising the bar: strategic multi-criteria decision analysis. Journal of the Operational Research Society, 62(5), 855-867. http://dx.doi.org/10.1057/jors.2009.178

Moro, A., \& Nolte, S. (2012). Entreprenuer historical performance, firm's survival rate and the expected return to equity: a probabilistic approach. European financial management association annual meetings. Barcelona.

Mutikanga, H., Sharma, S., \& Vairavamoorthy, W. (2011). Multi-criteria decision analysis: A strategic planning tool for water loss management. Water Resource Managment, 25(14), 3947-3969. http://dx.doi.org/10.1007/s11269-011-9896-9

Nichols, F. (2005). Strategic decision making: Commitment to strategic action. Retrieved March 20, 2005, from http://www.nickols.us/strategic_decision_making.pdf 
Nichols, F. (2010). Three forms of strategy: General, corporate and competitive. Retrieved April 1, 2013, from http://www.nichols.us/three_forms.pdf

Nutt, P. (1999). Surprising but true: Half the decisions in organizations fail. Academy of Management Executive, 13(4), 75-90. http://dx.doi.org/10.5465/AME.1999.2570556

Nutt, P. (2005). Search during decision making. European Journal of Operational Research, 160(3), 851-876. http://dx.doi.org/10.1016/j.ejor.2003.07.009

O'Brien, F. (2011). Supporting the strategy process: A survey of UK OR/MS practitioners. The Journal of the Operational Research Society, 62(5), 900-920. http://dx.doi.org/10.1057/jors.2011.2

Oliveira, A. (2007). A discussion of rational and psychological decision-making theories and models: The search for a cultural-ethical decision-making model. Electronic Journal of Business and Organization Studies, 12(2), 12-17.

Papadakis, V., \& Barwise, P. (1988a). Strategic decisions. Berlin: Spinger-Verlag.

Papadakis, V., \& Barwise, P. (1988b). Strategic decisions: An introduction. In V. Papdakis, \& P. Barwise, Strategic decisions. New York: Kluwer Academic Publishers.

Porter, M. (2008). The five competitive forces that shape strategy. Havrad Business Review, 86(1), 78-93.

Rajagopalan, N., Rasheed, A., \& Datta, D. (1993). Startegic decision processes: Critical review and future directions. Journal of Management, 19(2), 349-384. http://dx.doi.org/10.1177/014920639301900207

Rajagopalan, N., Rasheed, A., \& Datta, D. (1997). A multi-theoretic model of strategic decision making. In V. Papadakis, \& P. Barwise, Strategic Decisions. New York: Kluwer Academic Publishers.

Ram, C., Montibeller, G., \& Morton, A. (2011). Extending the use of scenario planning and MCDA for the evaluation of strategic options. Journal of Operational Research Society, 62(5), 817-829. http://dx.doi.org/10.1057/jors.2010.90

Robbins, P., \& Coulter, M. (2003). Management (7 ed.). New Jersey: Prentice Hall. Retrieved from

http://sirpabs.ilahas.com/Management,\%207e,\%20Robbins-Coulter\%20\%28Student\%20Ed. \%29.pdf

Rosenhead, J. (1980). Planning under uncertainty: II. A methodology of robustness analysis. Journal of Operational Research Society, 31(4), 331-341. http://dx.doi.org/10.2307/2581626

Savage, L. (1954). The foundations of statistics. New York: Wiley.

Schneider, S. C., \& De Meyer, A. (1991). Interpreting and responding to strategic issues: The impact of national culture. Strategic Management Journal, 12(4), 307-320. 
http://dx.doi.org/10.1002/smj.4250120406

Schwenk, R. (1995). Decision making. Journal of Management, 21(3), 471-493. http://dx.doi.org/10.1016/0149-2063(95)90016-0

Simon H, A. (1947). Administrative behavior; a study of decision-making processes in administrative organization. New York: Free Press.

Simon, H. (1960). The new scinece of management decision. New York: Harper and Row.

Simon, H. A. (1957). Models of man: social and rational. Mathematical essays on rational human behavior in a social setting: New York, John Wiley.

Simon, H. A. (1979). Rational decision-making in business organizations. The American Economic Review, 69(4), 493-5413.

Slovic, A., \& Tversky, A. (1974). Who accepts Savages's axiom? Behavioral Science, 19(6), 368-373. http://dx.doi.org/10.1002/bs.3830190603

Suedel, B., Burks-Copes, K., Kim, K., \& McKay, K. (2011). Using multi-criteria decision analysis to support ecosystem restoration planning. EMRRP-EBA-07.

Suslick, S. B., \& Furtado, R. (2001). Quantifying the value of technological, environmental and financial gain in decision models for offshore oil exploration. Journal of Petroleum

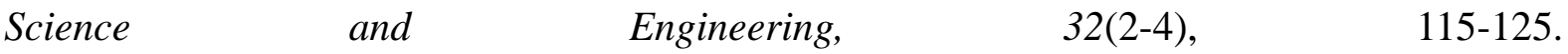
http://dx.doi.org/10.1016/S0920-4105(01)00154-1

Tsoukas, H., \& Knudsen, C. (2002). The conduct of strategy research. In A. Pettigrew, H. Thomas, \& R. Whittington, Handbook of strategy and management (pp. 441-435). London: Sage Publications.

Tversky, A., \& Kahneman, D. (1986). Rational choice and the framing of decisions. Journal of Business, 59(4), 251-278. http://dx.doi.org/10.1086/296365

Vassilev, V., Genova, K., \& Vassileva, M. (2005). A brief survey of multi-criteria decision making methods and software systems. Cybernetics and Information Technologies, 5(1), 3-14.

Vincke, P. (1992). Multi-criteria decision-aid. New York: John Wiley and Sons.

Weiner. (1974). Achievement motivation and attribution theory. Morristown, N.J: General Learning Press.

Weirich, P. (2004). Realistic decision theory: Rules for non-ideal agents in non-ideal circumstances. Oxford: Oxford University Press.

Williams, S. (2002). Making better business decisions: Understandingand improving critical thinking in problem-solving skills. London: Sage Publications Incorporation.

\section{Glossary}


$\mathrm{DM}$

Decision Making

INFORMS Institute for Operations Research and the Management Sciences

MAU Multi-Attribute Utility

MAUT Multi-attribute Utility Theory

MCDA Multi-Criteria Decision Analysis

MS Management Science

MSME $\quad$ Micro, Small and Medium size Enterprises

SAU

Single Attribute Utility

SDM

Strategic Decision Making

SEU

Subjective Expected Utility

SME

Small and Medium size Enterprises

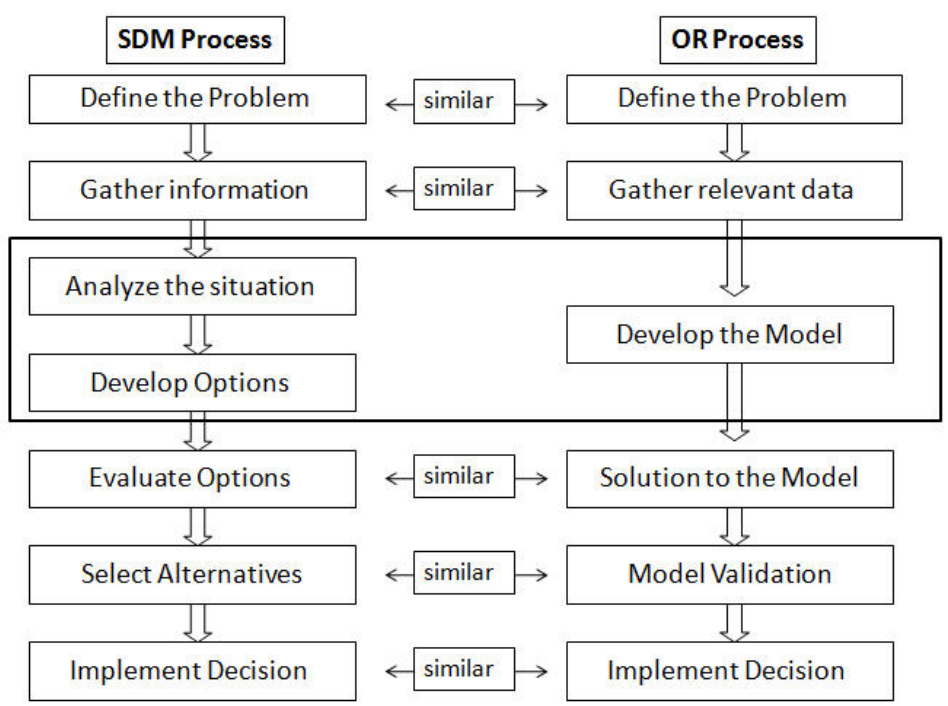

Figure 1. The relationship between SDM and MS processes 


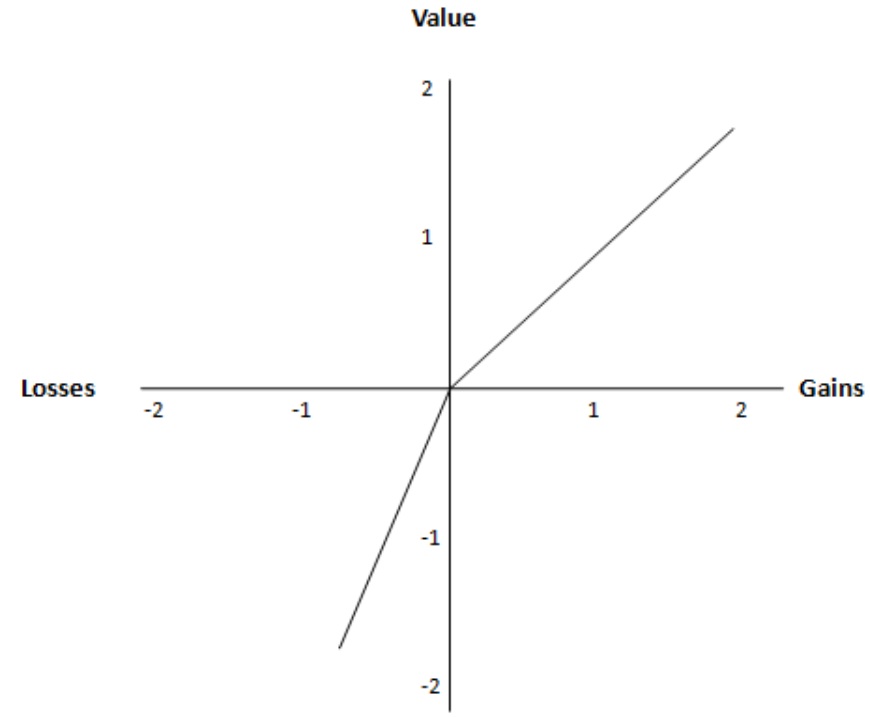

Figure 2. A hypothetical value function

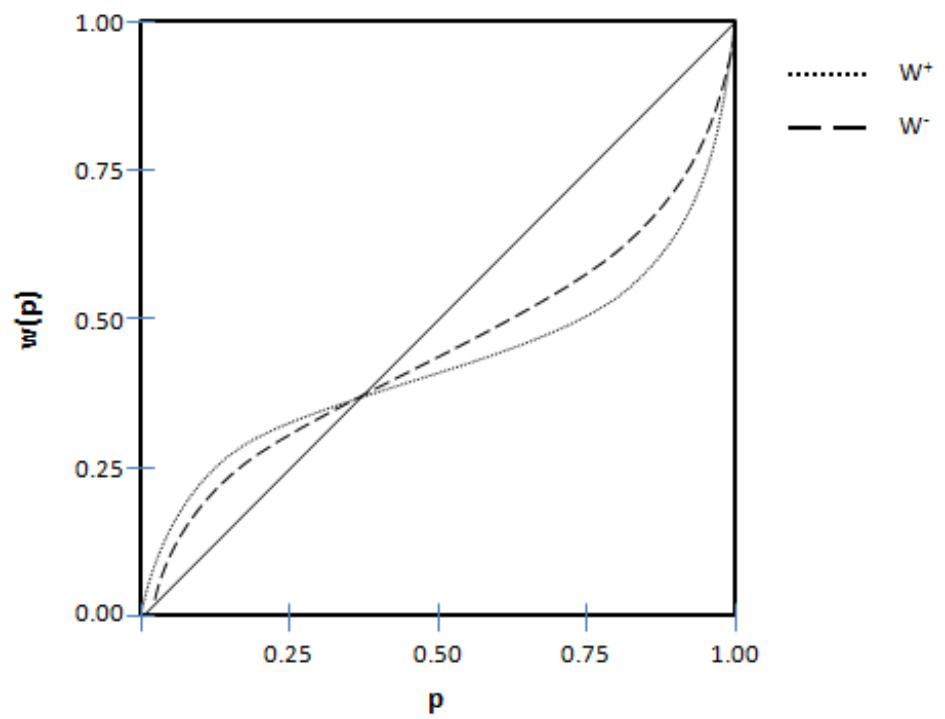

Figure 3. The weighting functions for gains $\left(\mathrm{w}^{+}\right)$and losses $\left(\mathrm{w}^{-}\right)$

Figure 4. The classical decision-making process (Nichols, 2005) 


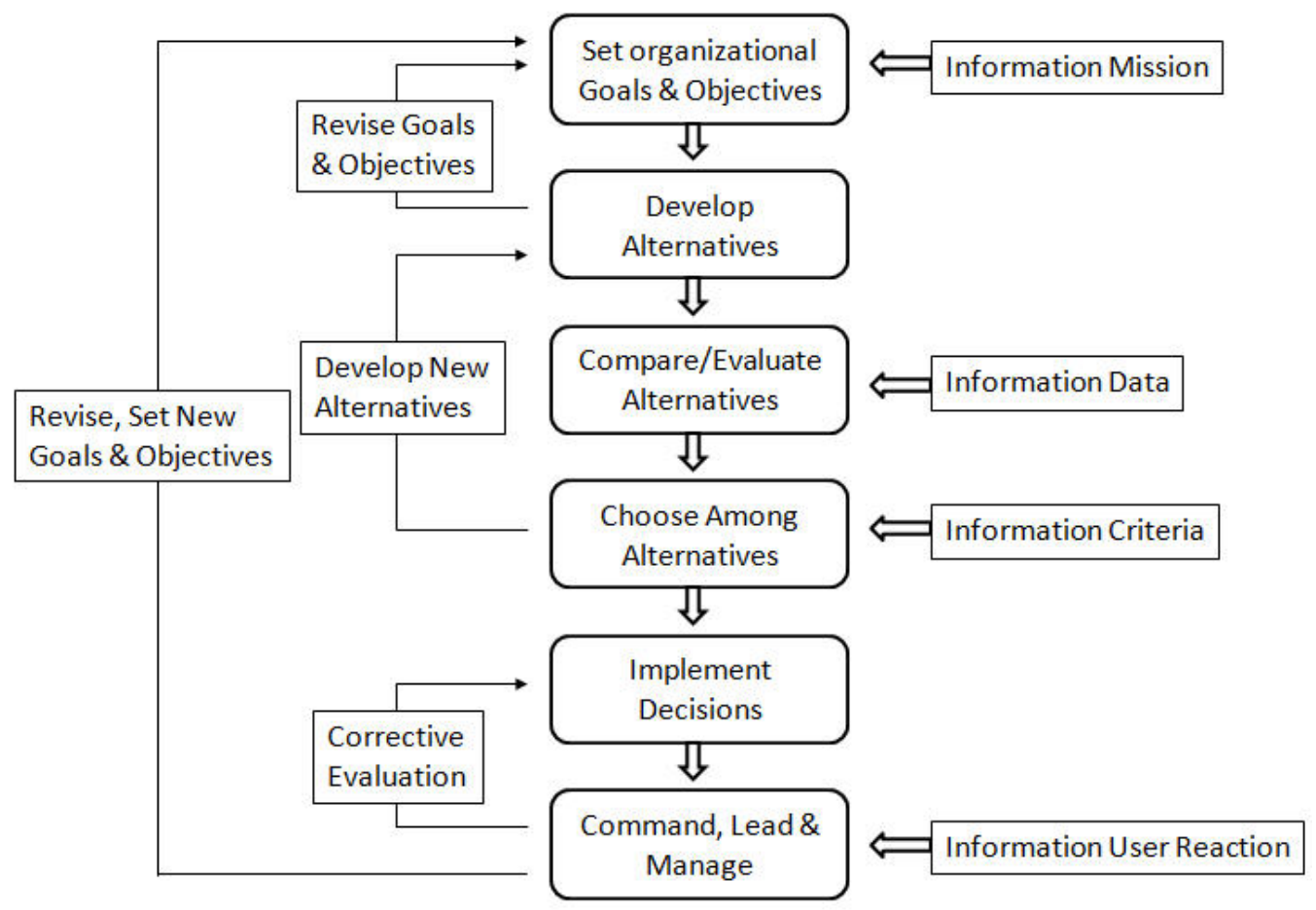

Figure 5. The military model (Nichols, 2005)

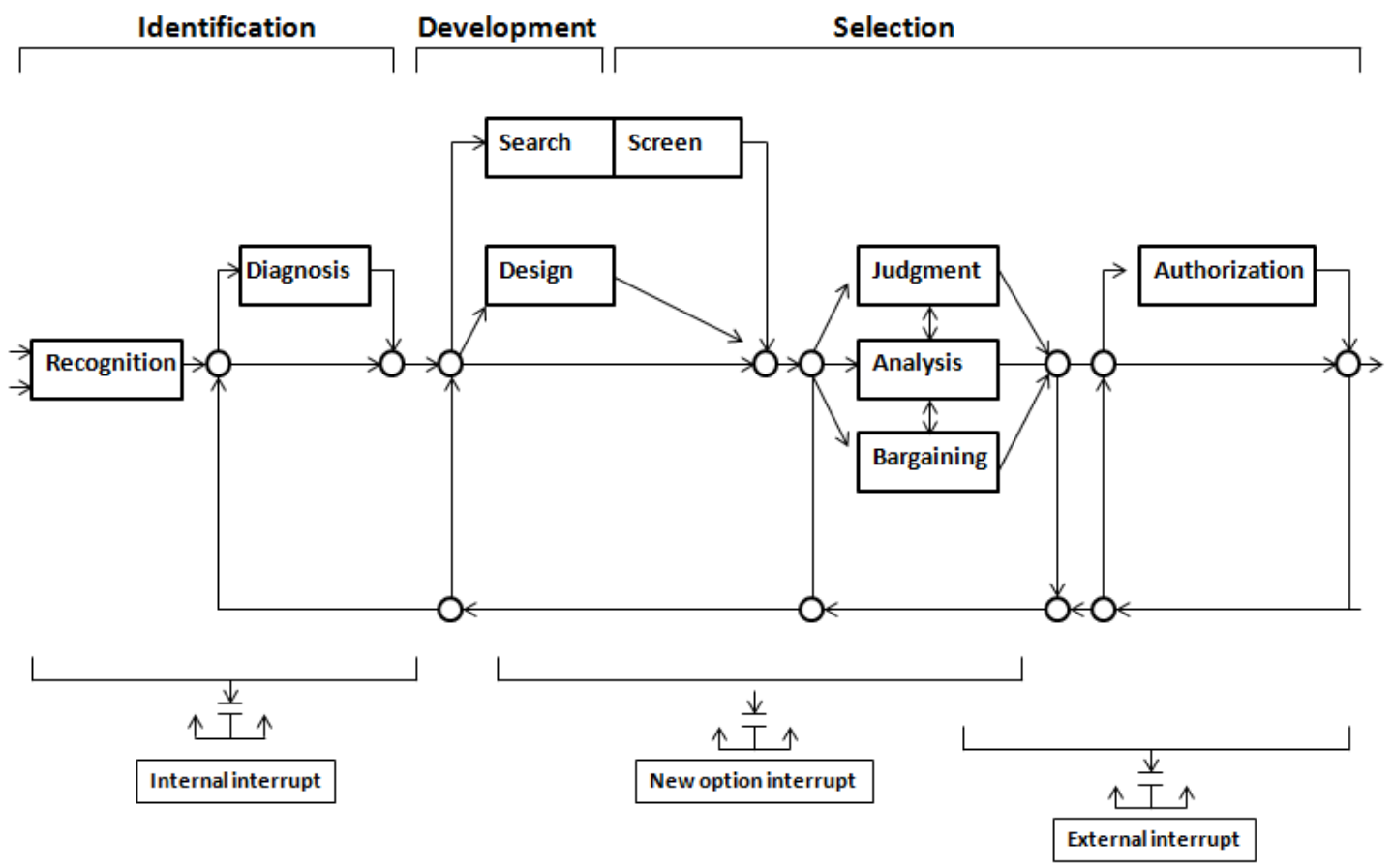

Figure 6. Mintzberg model 


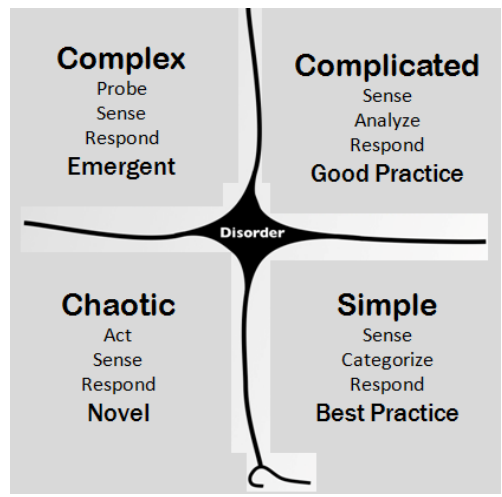

Figure 7. Cynerfin model

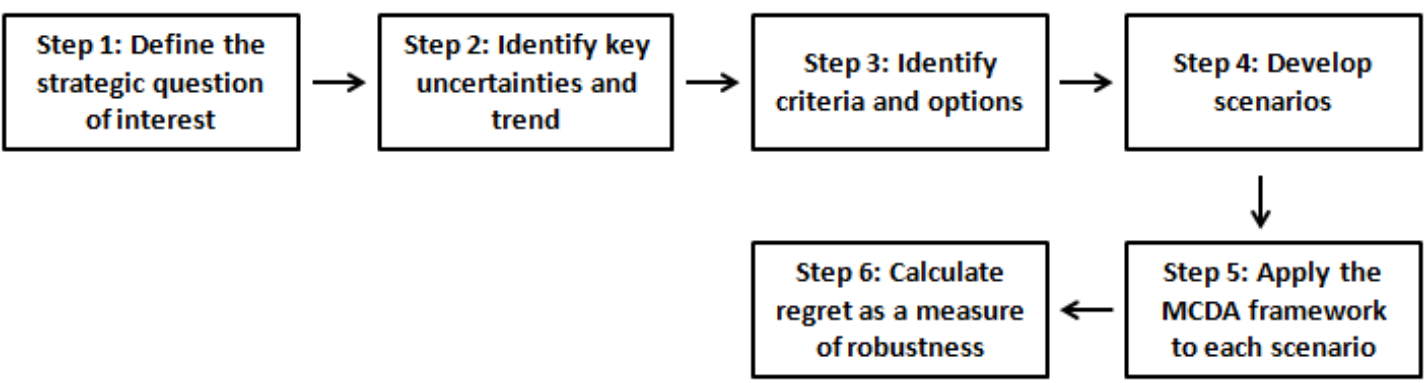

Figure 8. A six-step framework

Table 1. Differences between rational and non-rational theories

\begin{tabular}{|l|l|}
\hline Rational approach & Non-rational approach \\
\hline $\begin{array}{l}\text { Rational theories are based on the idea of } \\
\text { optimization where a function is } \\
\text { maximized (or minimized) for certain } \\
\text { variables across a number of alternatives. }\end{array}$ & $\begin{array}{l}\text { Non-rational theories dispense with the ideal of } \\
\text { optimization where mathematical programming } \\
\text { techniques are not used. }\end{array}$ \\
\hline $\begin{array}{l}\text { Normative decision theory concerns with } \\
\text { making decisions under certain } \\
\text { assumptions. It means that given some } \\
\text { properly defined choices, the decision } \\
\text { maker will make consistent decisions } \\
\text { types. }\end{array}$ & $\begin{array}{l}\text { In contrast, descriptive theories (or behavioural } \\
\text { theory) are concerned with how people actually } \\
\text { make decisions. It accepts the fact that people } \\
\text { are often inconsistent and that factors other than } \\
\text { narrow view of rationality affect the decisions } \\
\text { made. Descriptive decision theory discusses, } \\
\text { for example, the paradox that when people have } \\
\text { more options available they often make worse } \\
\text { choice (Hansson, 2005). }\end{array}$ \\
\hline
\end{tabular}


Rational theories assume omniscience, In contrast, non-rational theories have to search that is, all the relevant information is for information either from primary or already available to the decision maker. secondary data sources.

Source: Gigerenezer (2001)

Table 2. Differences between rational and bounded rationality

\begin{tabular}{|l|l|l|}
\hline Decision-making step & Rational decision-making & Bounded rationality \\
\hline Problem definition & Real problem is identifiable. & $\begin{array}{l}\text { Problem primarily reflects the } \\
\text { decision interest, } \\
\text { understanding, and needs. }\end{array}$ \\
\hline Criteria definition & $\begin{array}{l}\text { All relevant criteria are } \\
\text { identifiable and weighted } \\
\text { appropriately. }\end{array}$ & $\begin{array}{l}\text { Limited criteria are identifiable, } \\
\text { and evaluation is influence by } \\
\text { self-interest. }\end{array}$ \\
\hline $\begin{array}{l}\text { Alternative generation } \\
\text { and evaluation }\end{array}$ & $\begin{array}{l}\text { All options are considered, } \\
\text { and consequences are } \\
\text { understandable and taken into } \\
\text { consideration. }\end{array}$ & $\begin{array}{l}\text { Limited options are identified, } \\
\text { favored option is given priority, } \\
\text { and consideration halts when a } \\
\text { "good enough" solution is found. }\end{array}$ \\
\hline Implementation & $\begin{array}{l}\text { All participants understand } \\
\text { and support the solution. }\end{array}$ & $\begin{array}{l}\text { Politics, power, and self-interest } \\
\text { influence the amount of } \\
\text { acceptance and commitment to the } \\
\text { solution. }\end{array}$ \\
\hline
\end{tabular}

Source: Williams (2002, p.15) 